\title{
What is the role of clinical ethics support in the era of e-medicine?
}

Michael Parker and J A Muir Gray University of Oxford,

\begin{abstract}
The internet is becoming increasingly important in health care practice. The number of health-related web sites is rising exponentially as people seek

health-related information and services to supplement traditional sources, such as their local doctor, friends, or family. The development of e-medicine poses important ethical challenges, both for health professionals and for those who provide clinical ethics support for them. This paper describes some of these challenges and explores some of the ways in which those who provide clinical ethics support might respond creatively to them. By offering ways of responding to such challenges, both electronically and face-to-face, the providers of clinical ethics support can show themselves to be an indispensable part of good quality health care provision (Fournal of Medical Ethics 2001;27 supp1 I:i33-i35)
\end{abstract}

Keywords: e-medicine; clinical ethics; internet; quality of information; bioethics

\section{Introduction}

Fujitsu-Siemens project that by 2002 there will be around 380 million users of the internet worldwide. There are currently 2.1 billion indexible web pages and the total number of pages is thought to be in the tens of billions. ${ }^{1}$ The web is growing at a rate of seven million pages a day.

Health care is one of the most popular reasons for accessing the internet. Increasingly, people are seeking health-related information and services to supplement (and perhaps to replace) traditional sources such as discussion with their local doctor, friends, or family. There are currently between 15,000 and 100,000 indexible health-related sites based in the United Kingdom. In 1999, healthrelated sites were visited by 30 million people from the United Kingdom, and it is estimated that this figure will have risen to 50 million in 2000 [personal communication, Tom Wilkie, 2000].

The changes being brought about by the development of the internet and other digital technologies are not, however, merely quantitative. Their impact inevitably has an important qualitative dimension, changing the way in which we understand ourselves and our health. ${ }^{2} \mathrm{~A}$ wide range of interrelated technological developments is going to contribute further to this process of qualitative change: the impending merger of digital television and personal computers, and the growth in the power and integration of mobile points of access (WAP phones, palmtops and so on) will be impor- tant factors. In the field of health care, we will soon carry "smart cards" on which personal health care information will be recorded for easy access in emergencies (CD versions of something like this exist already). Perhaps too we will wear smart body-monitors which will record our health state and remind us of our nutritional intake requirements. ${ }^{3}$ Perhaps these will be linked to the local hospital or to the local supermarket checkout, or to the gym.

What are the implications of the growth in e-medicine for clinical ethics? In this paper we describe some of the potential challenges and opportunities offered to clinical ethics support by such developments.

\section{Challenges}

\section{(I) ACCESS TO INFORMATION}

Traditionally, nominated health professionals have been the only, or at least the most powerful, "gateways" to health care information. This has already changed to some extent with the growth of consumer groups, patient support networks and popular publications focusing on health matters. Nevertheless, the continued growth of e-medicine is set to change this in ways unimaginable even five or ten years ago. With the emergence of a variety of both official and unofficial online sources of information available globally health-related information will no longer respect boundaries, other than those between people who have access to the internet and those who do not. The internet offers immediacy of communication, of information and of the internetworking of people, combined with the near impossibility of regulation or control of information flows.

Access to information is in itself clearly insufficient, however, for good judgment. More information does not equal better information. A key challenge for the future will be finding ways to enable consumers, and indeed health professionals, to tell the difference between good information and bad. A study by American gastroenterologists found that one in ten of the health-related sites in the field offered unproven treatments. ${ }^{4}$

The porosity of borders to information must inevitably lead to a weakening of policy-making power and the power to regulate and to maintain standards. Moreover, much of the information available to the public and to health professionals will be provided by pharmaceutical companies or by those, such as patient support groups, who are 
attempting to exert pressure in order to bring a drug to the market. What will be the role of those who provide clinical ethics support in this context?

\section{(II) ACCESS TO TREATMENTS}

People will increasingly spend their discretionary income on health care in their own way. This may involve purchasing treatments or genetic tests over the internet or it may involve travelling for treatment they have learned about on the web. If a treatment is not available in their jurisdiction people will go elsewhere to find it. ${ }^{5}$ This need not only involve expensive high-tech treatments-a more everyday example might be a woman from a country where termination or the "morning after" pill is banned on religious grounds who uses the internet to gain access to drugs through the post, or to information (including travel instructions) about a centre in another jurisdiction willing to carry out the procedure.

One possible consequence of the availability over the internet of drugs taken without supervision may be an increase in the number of people turning up in accident and emergency departments having used unlicensed drugs or having used drugs inappropriately. Who will be liable for the misuse or mis-selling of treatments if a drug is bought from a drug company, or if clinical advice is given over the internet by a clinician in a distant country? This raises important questions about the role of nationally funded health services and about the ability of finance ministries to manage health care spending. But it also raises important questions about confidentiality and clinical responsibility. One implication is likely to be that those who provide clinical ethics support in different national health trusts in the UK, or even in different countries, are going to have to find new ways of working together-perhaps using the internet.

A particularly interesting cluster of ethical questions may also begin to arise out of the ever closer relationship between clinical practice and research. The fact that, increasingly, the public will be likely to have electronic access to information about the progress of drug trials before they are completed, for example, may lead them to demand to be allowed to be research subjects in order to get access to new treatments. Or they may demand information about untested and unregulated and unregistered drugs. How will ethics committees (both clinical and research) respond to such demands? Clinical and research ethics committees will have to work out ways of working together.

\section{(III) COMMERCIALISATION}

Direct to consumer advertising (DTCA) is an inevitable consequence of the development of the web. Even though DTCA is banned in some jurisdictions, web sites from around the world containing it are accessible, as are the home pages of pharmaceutical companies. This means that the relationship between pharmaceutical companies and the public is set to become increasingly unmediated. One advantage of this may be that such companies will become more responsive to public demand. But such a relationship is more likely to pose important ethical challenges - the information available on such sites is very likely to be biased or limited in scope.

There is only a limited sense in which "independent" sources of information will be able to counter this. Commercial forces mean that the independence of health information sites other than those of pharmaceutical companies themselves cannot be guaranteed. The requirement for advertising revenue is one pressure. Moreover, the experience of DrKoop. $\mathrm{com}^{4}$ shows that advertising itself is unlikely to bring in sufficient income to keep a site going and that a closer commercial relationship between such sites and commercial companies will be required if they are to remain viable. Who will take on responsibility for the provision of quality-evaluated health information and indeed information about the ethical implications of developments in medicine and medical science?

\section{Opportunities}

Whilst the development of the internet and of the worldwide web poses important challenges for clinicians and for those who provide ethical support to them, such as clinical ethics committees and clinical ethicists, it also offers opportunities to meet such challenges, and ways of developing new and more responsive forms of ethics support. Some of these have been hinted at above, but below we sketch some possible ways in which the internet might be used to enhance the provision of clinical ethics support.

(I) MORE EFFICIENT AND FLEXIBLE CLINICAL ETHICS SUPPORT FOR CLINICIANS

Clinical ethics committees are well established in the United States but are a relatively recent phenomenon in the United Kingdom and elsewhere. Yet the committee meeting as such may already be in need of rethinking. Currently clinical ethics committees meet relatively infrequently, perhaps once a month or so. The ethical issues presented by clinical practice are not limited in this way. Health professionals face ethical challenges on a daily basis. The web offers the opportunity to develop forms of clinical ethics support of a much more flexible and ongoing kind, less determined by geography and the availability of members for physical meetings. The internet and e-mail mean that ethics support might be provided through the use of moderated discussion lists, case consultation services and so on. This also means that support would be available to those who work in remote communities.

In addition to case consultation, committees will continue to be involved in the development of policy. The web will make it possible for this to be a much more inclusive and responsive process where policies are perhaps posted on controlled access sites as "requests for comment" from staff members and/or the local community. These policies could 
be updated on a regular basis. The web also makes it much easier for the committee to co-opt non-members to assist with a particular decision or policy development. For committees who do not have access to an ethicist, for example, this offers one way in which such support might be accessed perhaps from another committee or geographica location. The internet offers the possibility for committees to pool their resources.

(II) COMMUNICATION BETWEEN COMMITTEES

A national network of clinical ethics committees has recently been established in the United Kingdom ${ }^{7}$ as a result of demand from the members of clinical ethics committees themselves for just this kind of mutual support. The aim of this network, which meets annually, produces a newsletter and provides training for committee members, is to facilitate the contacts between committees and the sharing of experiences. This process could be made much easier and more efficient through the use of the internet: through the creation of electronic newsletters, thematic discussion lists, databases of policies, training materials and skill resources etc.

(III) EDUCATION AND TRAINING

The internet also offers the possibility of developing innovative forms of ethics education and training at a distance for members of clinical ethics committees and also for health professionals. The education of health professionals about ethical issues and about policies of national health trusts is a key function of clinical ethics committees and members of committees often express their wish for more training on ethical issues. The web offers the possibility of developing online education (textbooks, interactive courses and training). One particular advantage of this approach to training is the possibility it offers of continuously updating such education and textbooks in the light of policy changes, new cases, discussion and feedback from users. There is in effect the possibility of committee members creating an open-ended textbook for themselves.

\section{Some concluding remarks}

The development of e-medicine poses important ethical challenges for health professionals and for those who provide clinical ethics support. In this paper we have sketched out some of the ways in which committees and clinical ethicists might respond creatively to such challenges. The next few years have the potential to be an exciting time in the development of ethics support in the clinical setting. Clinical ethics committees and other forms of clinical ethics support will only prosper however, if they are able to show themselves to be of real use to health professionals and patients. True, the internet offers many ethical challenges but by offering health professionals ways of responding to such challenges both electronically and face-toface, the providers of clinical ethics support can show themselves to be an indispensable part of good quality health care provision.

Michael Parker BEd, PhD, is Clinical Ethicist at the Radcliffe Hospitals NHS Trust and University Lecturer in Medical Ethics in the Department of Public Health and Primary Care, University of Oxford. $\mathcal{f}$ A Muir Gray, CBE, DSc, MD, FRCP (Glas \& Lond), is Director of the Institute of Health Sciences, Oxford.

\section{References}

1 www.cyveillance.com (accessed 14/8/2000).

2 Beck U. The brave new world of work. Cambridge: Polity, 2000. 3 See, http://news.bbc.co.uk/hi/english/sci/tech/newsid_882000/ $882254 . \mathrm{stm}$

4 Barkham P. Is the net healthy for doctors? The Guardian Online 2000 Jun 8: 2 .

5 This is already happening. See for example, http:// news6.thdo.bbc.co.uk/hi/english/health/newsid\%5F856000/ 856764.stm (accessed 29/7/2000)

6 One such service is provided in the United Kingdom by http:// Omni.ac.uk. The Wellcome Trust is also currently funding the development of an electronic bioethics resource, The UK Bioethics and Society Network (contact Dr Michael Parker on michael.parker@ethox.ox.ac.uk, for details about this). Dr Parker is also developing a gateway for quality-evaluated bioethics resources on the web.

7 Slowther A, Bunch C, Woolnough B, Hope T. Clinical ethics support in the UK: a review of the current position and likely development. London: The Nuffield Trust (in press). 